\title{
Modeling environmental services in rivers at catchment scale
}

\author{
José-Miguel Sánchez-Pérez ${ }^{1,2 *}$, Sabine Sauvage ${ }^{1,2}$ and Raghavan Srinivasan ${ }^{3}$ \\ ${ }^{1}$ Laboratoire Ecologie Fonctionnelle et Environnement (EcoLab), University of Toulouse, INPT, UPS, Avenue de l'Agrobiopole, \\ 31326 Castanet Tolosan Cedex, France \\ 2 EcoLab, CNRS, 31326 Castanet Tolosan Cedex, France \\ 3 Spatial Sciences Laboratory, Texas A\&M University, College Station, TX 77845, USA
}

Received 20 February 2015; Accepted 23 February 2015

Key words: Environmental services / modeling / watershed / rivers / SWAT / SENEQUE

Natural and anthropogenic pressures control water, sediment and pollutant transfer in different parts of a watershed through various pathways including surface and groundwater. In addition to these control factors, many physical, chemical and biological processes are also involved. These functions can be considered as environmental or ecosystem services with regards to the degradation of pollutants, for example the denitrification process in a riverbed or at a river/aquifer interface in riparian areas. The role of these environmental services can be difficult to evaluate and in many cases are included in a global sink. However, it is important to note their effect on the transportation of matter and pollutants in a watershed. To evaluate these functions, these processes need to be characterized and quantified. Catchment scale is an integrative scale used to evaluate environmental services. Integrated modeling is a way of evaluating the transfer of water, matter and pollutants and the role of environmental services involved. An overview of the papers presented in this issue follows and they illustrate environmental services at catchment scale. The research is based on work presented at the SWAT 2013 international conference in Toulouse, France.

Riverbed sediment affects water quality at reach scale where the contribution of nutrients comes from the landscape. To evaluate the role of the benthic interface, the processes need to be characterized first at reach scale. Billen et al. (2015) have proposed a new module based on the response of Thouvenot's model to the various constraints affecting benthic processes, according to a conceptual, interpretative framework relating the nutrient fluxes across the sediment-water interface. It is possible to calculate the fluxes of dissolved nutrients and oxygen across the water-sediment interface integrating organic matter degradation, provided that the concentration of

\footnotetext{
*Corresponding author: jose.sanchez@univ-tlse3.fr
}

these nutrients in the water column, as well as a number of properties of the upper fluid layer of the sediment, can be measured or estimated. The validity of this new algorithm as regards the original equations has been verified on the basis of the results of a run of the Seneque/Riverstrahler model on the entire drainage network of the Seine River, providing a comparison of more than 15000 different situations. The proposed new algorithm will replace the original equations in future versions of the Riverstrahler model due to its significantly shorter computation time and its numerical stability. It also constitutes a generic module for calculating benthic fluxes that can be implemented into any other model of nutrient dynamics in lentic or lotic ecosystems at a larger scale.

Suspended sediment transportation and associated pollutants from catchment to stream networks are responsible for aquatic habitat degradation, reservoir sedimentation and the transportation of sediment-bound pollutants. Quantifying the suspended sediment loads from land to river is essential for controlling soil erosion and implementing appropriate mitigation practices to reduce stream sediment and associated pollutant loads, and hence improve surface water quality downstream. De Girolamo et al. (2015) have tested an approach aimed at supporting the ecological quality assessment at river reach scale of intermittent streams in the Salsola and Celone river basins in south-east Italy, by using integrated hydrological modeling and analyzing the hydrological alterations due to anthropogenic pressures. Peraza-Castro et al. (2015) have evaluated the temporal variability of hydrology, sediment and nickel loads using the Soil Water Assessment Tool (SWAT) in the Oka watershed $\left(32 \mathrm{~km}^{2}\right)$, located in northern Spain in oceanic climatic conditions. Wang et al. (2015) have used SWAT in a study conducted in the Shibetsu River watershed $\left(672 \mathrm{~km}^{2}\right)$ in Hokkaido, Japan to understand the dynamics of sediment, 
particulate organic nitrogen $(\mathrm{PON})$ and particulate organic phosphorous (POP).

Biem Mori et al. (2015) have evaluated landscape influences on the physical and chemical composition of stream water in 15 agricultural catchments at different spatial scales (catchment and riparian). In addition, the relationship has been analyzed between water characteristics and landscape structure variables in the Corumbatai river basin (areas ranging from 98 to $600 \mathrm{ha}$ ) as a sub-basin of the Piracicaba river basin in Brazil.

The main results of the research showed that:

- the SWAT model is an integrated model useful for: (a) providing a better understanding of the spatial and temporal dynamics of flow, sediments, nitrates, phosphates and pollutants such as metals that can be linked to land use and anthropogenic activities, and (b) quantifying the sources of erosion, transport and natural degradation in a hydrologic cycle, providing insight into the potential impact on ecological habitats in the river network

- changes in land cover, especially the replacement of forest by agricultural activities, affect the hydrological processes of river catchments, resulting in physical and chemical compositional changes of water draining from affected basins

- there is a higher concentration of nitrate in sugarcane fields and larger amounts of suspended solids and turbidity in pasture areas

- degraded and highly fragmented forests may not make an effective contribution toward the protection of aquatic ecosystems

- river-type classifications, an analysis of the different sets of meso-habitats which can occur in a reach in a certain period, and hydrological status (the divergence of the impacted (actual) regime from its natural condition) are three different aspects that are relevant for supporting the assessment of the ecological status

- in the Shibetsu River watershed $\left(672 \mathrm{~km}^{2}\right)$, the simulated annual sediment yield ranged from 5 to $45 \mathrm{t} \cdot \mathrm{km}^{2} \cdot \mathrm{yr}^{-1}$ (annual mean of $24 \mathrm{t} \cdot \mathrm{km}^{2} \cdot \mathrm{yr}^{-1}$ ), annual PON (expand) yield ranged from 0.1 to $0.3 \mathrm{t} . \mathrm{km}^{2} \cdot \mathrm{yr}^{-1}$ (annual mean of $0.18 \mathrm{t} \cdot \mathrm{km}^{2} \cdot \mathrm{yr}^{-1}$ ), and annual POP (expand) yield ranged from 0.01 to $0.03 \mathrm{t} . \mathrm{km}^{2} \cdot \mathrm{yr}^{-1}$ (annual mean of $0.02 \mathrm{t}^{\mathrm{k}} \mathrm{km}^{2} \cdot \mathrm{yr}^{-1}$ ). Peraza-Castro et al. (2015) have evaluated the temporal variability of hydrology, sediment and nickel loads using the SWAT model in the Oka watershed $\left(32 \mathrm{~km}^{2}\right)$ and the annual production of simulated sediments shows variability between 21 and $48 \mathrm{t} \cdot \mathrm{km}^{2} \cdot \mathrm{yr}^{-1}$ (annual mean of $33 \mathrm{t} \cdot \mathrm{km}^{2} \cdot \mathrm{yr}^{-1}$ ). The annual load of nickel simulated ranged from 1.01 to $2.28 \mathrm{t} . \mathrm{km}^{2} . \mathrm{yr}^{-1}$ (annual mean of $1.63 \mathrm{~kg} \cdot \mathrm{km}^{2} \cdot \mathrm{yr}^{-1}$ ).

These results show that further studies are needed to formulate the relationship between hydrological and biogeochemical alterations and ecological response in order to clearly define the relationships between hydrological and biogeochemical processes and their overall impact. In order to quantify environmental functions on a larger scale, it is important to study the processes on a smaller scale. Doing so allows parameters to be set and the process to be simulated in the right order to capture the spatiotemporal processes for integration into the modeling.

The importance of this research is to understand the long-term inter-annual variability of suspended sediment and associated pollutants, as well as to identify the contributing landscape areas and impacted/non-impacted reaches for ecological functions to be active.

\section{References}

Biem Mori G., Rossetti de Paula F., Frosini de Barros Ferraz S., Monteiro Camargo A.F. and Martinelli L.A., 2015. Influence of landscape properties on stream water quality in agricultural catchments in Southeastern Brazil. Ann. Limnol. - Int. J. Lim., 51, 11-21.

Billen G., Garnier J. and Silvestre M., 2015. A simplified algorithm for calculating benthic nutrient fluxes in river systems. Ann. Limnol. - Int. J. Lim., 51, 37-47.

De Girolamo A.M., Gallart F., Pappagallo G., Santese G. and Lo Porto A., 2015. An eco-hydrological assessment method for temporary rivers. The Celone and Salsola rivers case study (SE, Italy). Ann. Limnol. - Int. J. Lim., 51, 1-10.

Peraza-Castro M., Montoya-Armenta L.H., Sánchez-Pérez J.M., Sauvage S. and Ruiz-Romera E., 2015. Evaluation of hydrology, suspended sediment and nickel loads in a small watershed in the Basque Country (Northern Spain) using the eco-hydrological SWAT model. Ann. Limnol. - Int. J. Lim., 51, 59-70.

Wang C., Jiang R., Mao X., Sauvage S., Sánchez-Pérez J.M., Woli K.P., Kuramochi K., Hayakawa A. and Hatano R., 2015. Estimating sediment and particulate organic nitrogen and particulate organic phosphorous yields from a volcanic watershed characterized by forest and agriculture using SWAT model. Ann. Limnol. - Int. J. Lim., $51,23-35$. 